\title{
Acquisition outcomes across domains in adult simultaneous bilinguals with French as weaker and stronger language ${ }^{1}$
}

\author{
TANJA KUPISCH ${ }^{a, b}$, TATJANA LEIN ${ }^{c}$, DAGMAR BARTON ${ }^{a}$, \\ DAWN JUDITH SCHRÖDER ${ }^{a}$, ILSE STANGEN ${ }^{a}$ AND \\ ANTJE STOEHR ${ }^{\mathrm{d}}$ \\ ${ }^{a}$ University of Hamburg \\ ${ }^{\mathrm{b}}$ Lund University \\ ${ }^{c}$ University of Bremen \\ ${ }^{\mathrm{d}}$ CLS, Radboud University Nijmegen/IMPRS for Language Sciences, Nijmegen, The Netherlands
}

(Received August 20I2; revised March 20I3; first published online 2 August 20I3)

\section{A B S T RACT}

This study investigates the adult grammars of French simultaneous bilingual speakers (2LIs) whose other language is German. Apart from providing an example of French as heritage language in Europe, the goals of this paper are (i) to compare the acquisition of French in a minority and majority language context, (ii) to identify the relative vulnerability of individual domains, and (iii) to investigate whether 2Lis are vulnerable to language attrition when moving to their heritage country during adulthood. We include two groups of German-French 2Lis: One group grew up predominantly in France, but moved to Germany during adulthood; the other group grew up predominantly in Germany and stayed there. Performance is compared in different domains, including adjective placement, gender marking, articles, prepositions, foreign accent and voice onset time. Results indicate that differences between the two groups are minimal in morpho-syntax, but more prominent in pronunciation.

\section{INTRODUCTION}

In the context of minority language acquisition research, use of the terms heritage speaker and heritage language is on the increase. According to standard definitions, a heritage language is acquired as a minority language within a majority language environment through naturalistic exposure in the home context (e.g. Rothman,

1 The research presented in this paper originated in project EII at the Research Centre of Multilingualism in Hamburg. We wish to acknowledge funding by the German Science Foundation granted to the first author. Part of the research we present is based on thesis work by Deniz Akpinar, Dagmar Barton, Tatjana Lein, Judith Schröder, Ilse Stangen and Antje Stöhr at the University of Hamburg. 
2009: I 56). The terms heritage speaker and heritage language have originally been used with reference to larger minorities, e.g. immigrants from Latin-America, Russia or South Korea to the US, and it has been claimed that the heritage (or minority) language may be subject to 'incomplete acquisition', i.e. 'non-nativelike attainment' (Montrul, 2008). In Polinsky's (I997: 37I) terms, incomplete acquisition means that 'a given grammar system undergoes a significant reduction [...] when it is passed on from one generation to the next'.

This study compares simultaneous bilinguals (henceforth 2LIs) who have grown up as heritage speakers of French (where German was the majority language) with speakers who have grown up as majority speakers of French (speaking German as a minority language). Contrary to claims raised in previous research, we show that heritage speakers are native-like in the domain of morpho-syntax. At the same time, their pronunciation tends to be perceived as non-native.

There have been many case studies on the development of French as a minority language, supporting the view that with consistent use of the minority language bilingual development is qualitatively like monolingual development (see the contributions in Meisel, I990, I994 and the overview in De Houwer, I995). These studies include children that match the definition of heritage speakers, although the term itself has not been used to describe them. The apparent contradiction between the aforementioned studies on adult bilinguals, showing incomplete acquisition, and child bilinguals, whose development resembles that of monolinguals, could mean two different things. Perhaps bilingual children acquire the heritage language completely but lose parts of it once entering school under massive majority-language input. For generative acquisition research, at least in syntax, this should be a rather unwanted assumption, because syntactic acquisition is assumed to be regulated by parameters, which are set early in life. Once these parameters are fixed, resetting is extremely costly or even impossible (Müller, I993; Meisel, I995). Alternatively, different acquisition outcomes might have nothing to do with bilingualism per se: they could be due to different methods (e.g. experimental vs. naturalistic data), different input conditions for the heritage language (e.g. bilinguals in bi-national vs. monolingual families), different educational backgrounds, or a different attitude of the society towards the language.

We are unaware of any studies on adult bilingual French speakers in Europe with a strict focus on $2 \mathrm{Lis}$, i.e. the adult counterpart to the aforementioned child studies. ${ }^{2}$ For the present study, we therefore selected an adult population of heritage speakers comparable to the child bilinguals studied in Meisel (I990, I994), comparing them to majority speakers of French. The heritage speakers lived predominantly in Germany, where access to French is facilitated through TV, geographical vicinity, bilingual kindergartens and schools, and foreign language teaching.

2 There are some studies on adult French bilinguals in the U.S. and in Canada (e.g. Bullock and Gerfen, 2004; Sundara, Polka and Baum, 2006; Sundara and Polka, 2008; MacLeod and Stoel-Gammon, 2009), but the conditions for bilingualism are different. 
The first issue we are exploring is the effect of the acquisition context, i.e. the dominant language of the society during childhood and adolescence. According to some studies (e.g. Müller and Hulk, 200I), the more proficient or dominant language of developing bilinguals need not coincide with the majority language spoken in the national environment. The question is whether this also holds for adult bilinguals.

The second matter we investigate is whether linguistic domains are affected differently by the quantity of input. Bilingual children's input space is divided between two languages. Nevertheless, morpho-syntax does not seem to pose particular problems in bilingual development: Bilingual children develop their two languages separately, go through the same acquisition stages as monolinguals and make the same types of developmental errors (e.g. Meisel, 20 I I for an overview), although they may go through these stages faster or more slowly (e.g. Paradis and Genesee, I996). In contrast to their morpho-syntactic abilities, bilingual children may have a smaller lexicon than monolinguals, especially in the minority language (Pearson et al., I997). In their phonetic and phonological development, bilinguals may differ from monolinguals but differences are mostly quantitative, resulting in delays (see Genesee and Nicoladis, 2007 for an overview). In summary, different components of language pose different degrees of difficulty in development. An open question remains whether these degrees are mirrored in linguistic systems at their end states.

The third point we address is the possibility of non-pathological language loss or language attrition in $2 \mathrm{LIs}$. While the concept of incomplete acquisition is typically associated with second generation immigrants, that of attrition is said to be characteristic of first generation immigrants, i.e. Polinsky's (I997) 'forgetters'. LI attrition can occur after immigration to a country which provides few opportunities to use the Li. It is more likely to affect the lexicon than other aspects of the language, such as morpho-syntax (Andersen, I982; Paradis, 2009; Schmid and Köpke, 2008). According to Montrul (2008: I67), attrition 'manifests itself as lexical retrieval difficulties and minor quantitative changes in pronunciation (phonetics/phonology)'. For phonology, Andersen (I982) proposes that 'distinctions that carry a high functional load will be maintained by an LA [ = language attriter] longer than phonological distinctions that carry a low functional load' (I982: 95), suggesting that phonetic distinctions which do not go along with phonemic distinctions are relatively vulnerable, especially when they exist in only one of the two languages. To our knowledge, while there is a lot of work on LI attrition, little has been said about attrition in adult 2 Lis who moved to a country where their heritage language is spoken as a majority language. ${ }^{3}$ In this study, we investigate German-French bilinguals who moved to Germany as adults. We will show that although their input space was divided during their childhood, they do not appear to be particularly vulnerable to attrition during adulthood.

3 See, however, Flores' (2010) on bilinguals who returned to their parents' country of origin during childhood. 


\section{COMPARING ACROSS DOMAINS AND TASKS}

If bilinguals show deviances from monolinguals in their speech, this does not hold for all aspects of their language. Nevertheless, it is to date rather unclear how the different components of grammar compare to each other. Most scholars share the view that the syntax-pragmatics/ discourse interface ${ }^{4}$, an external interface, is most likely to be affected (see White, 2009 for an overview). The interaction between syntax and semantics, an internal interface, is considered to be less vulnerable (Sorace and Serratrice, 2009). Other interfaces have received comparatively little attention in 2 Li research.

Relatively better performance in one domain over another could also be due to the task that it was assessed with. It is known from L2 research that different tasks require different degrees of awareness and different types of knowledge (i.e. implicit vs. explicit) (Bialystok and Ryan, I985; Birdsong, I989). Oral imitation of (un)grammatical sentences, oral narrative tasks, and timed grammaticality judgments tasks (GJTs) are more likely to reveal implicit knowledge. Untimed GJTs, metalinguistic knowledge and fill-in-the-blank cloze-tests are more likely to involve analyzed, explicit knowledge, as speakers pay more attention to structure and form-meaning coordination. Naturalistic interviews involve the least amount of control, even if interviewees may consciously choose conversational topics that they find easy to talk about.

Learner types (e.g. naturalistic vs. instructed) may differ as to the type of task they find easy. Comparing L2 speakers with heritage speakers, Montrul (2009) suggested that with no time pressure to respond, L2 learners may access metalinguistic knowledge, leading to relatively high accuracy in tasks involving explicit knowledge. Heritage speakers tended to be more accurate than L2 learners in oral tasks, equally accurate as L2 learners in GJTs, and less accurate than L2 learners in written tasks.

Furthermore, depending on the task and the language tested, one and the same phenomenon may involve an interface or not. For instance, in a language like French, where article use is obligatory (with minor exceptions in particular contexts), semantic knowledge is not required to decide whether or not to use an article. Hence, a forced choice task with the options of using no article or a definite one can be resolved on the basis of syntactic knowledge alone. If, on the other hand, the learner must decide whether to use a definite or an indefinite article, he has to take the context into account and the condition may be said to involve an interface. $^{5}$

In summary, when comparing across phenomena, it seems to be relevant how these phenomena are tested, whether they involve an interface or not and whether

${ }^{4}$ In most of the relevant articles, the terms 'pragmatics' and 'discourse' are used interchangeably, which is also what we do.

5 According to Sorace and Serratrice (2009: I97), 'violations at the syntax-pragmatics interface typically lie on a gradient of acceptability (e.g. the 'redundant' use of an overt rather than a null pronoun to maintain reference in Italian), [while] some violations of syntax-semantics interface conditions give rise to clear ungrammaticality (...)'. 
this interface is internal or external. Keeping these points in mind, we will address the following questions:

I. Do the linguistic abilities of simultaneous French-speaking bilinguals differ depending on whether French was acquired in a minority-language context or a majority-language context?

2. Are there different acquisition outcomes depending on the linguistic domain?

3. Are simultaneous bilinguals particularly vulnerable to language attrition?

\section{PREVIOUS RESEARCH}

The domains selected for this study show differences between German and French, thus being potentially vulnerable in bilingual French. The original purpose of the research was to compare different types of interfaces, which motivated the investigation of adjective placement, gender and article use in generic utterances. While the research was ongoing, we discovered that our bilingual participants, even the minority speakers of French, performed very well, contrary to claims in previous research on adult bilinguals (see above). We therefore identified other potentially vulnerable domains, namely prepositions and global accent, based on the suggestions of native speakers of French, who conducted naturalistic interviews with our participants. The decision to study VOT followed from raters' comments in the foreign accent study.

In the following, we provide a brief description of each of the six properties, summarizing previous work, including research on Germanic-Romance language combinations other than German-French.

\subsection{Adjective placement}

In French, attributive adjectives can be placed pre- and postnominally, depending on syntactic, stylistic, phonological or pragmatic factors (Laenzlinger, 2000). There are adjectives with a fixed position. These include adjectives referring to color, shape, religion or nationality of the object denoted by the noun (see I), monosyllabic and quantificational adjectives, and adjective-noun strings in idiomatic expressions (see 2).

(I) Il porte un complet blanc. he wears a suit white 'He wears a white suite.'

(2) Après l'enterrement, elle a pleuré à chaudes larmes. after the funeral she has cried at hot tears 'After the funeral, she has cried her heart out.'

Other adjectives have two possible positions, depending on their meaning. In (3), the position of the adjective is determined by the noun. The DP expresses a spacial dimension in (3a) and a temporal dimension in ( $3 \mathrm{~b})$. 
(3) a. Ce chat à poils courts est inscrit this cat of hairs short is noted dans le livre des records. in the book of.the records

'This cat with short hair is mentioned in the Guinness Book of Records.'

b. Il s' est absenté de la réunion un court instant. he self is absented of the meeting a short moment 'He left the meeting for a short moment.'

In (4), the meaning is dependent on the wider context. Jeune can have the meaning of 'recent' (4a) or 'young' (4b). In the context of a 45-year-old woman giving birth, the latter is less plausible.

(4) Context: Hier, à 45 ans, Marie a donné naissance à yesterday at 45 years Marie has given birth to un bébé.

a baby

'Yesterday at the age of 45 Marie has given birth to a baby.'

a. Aujourd'hui, la jeune mère organise une today the young mother organizes a

fête. ('the recent mother') party

b. ?Aujourd'hui, la mère jeune organise une today the mother young organizes a fête. ('the young mother') party

In order to position French adjectives correctly, a speaker must know for each adjective if its position is variable and, if so, what conditions determine the variation. Semantic knowledge about the type of adjective may be sufficient to determine the position of adjectives, such as $(\mathrm{I}-3)$. Arguably, no semantic knowledge is needed if a learner has a default position for adjectives. Under this assumption, we could predict that adjectives like (I), which never appear prenominally, do not create any problems in acquisition. Expressions like those in (2) may be learnt and stored as chunks and require activation of the lexicon. For adjectives like (3), whose position depends on the meaning of the noun, it is possible that they have separate entries in the mental lexicon, each associated with a different meaning. They are thus similar to cases like (2). In (4), the wider context must be taken into account, which justifies the assumption that the syntax-pragmatic interface is involved here.

In German, attributive adjectives can only be placed prenominally, e.g. rotes Haus 'red house'; postnominal attributive adjectives are stylistic exceptions, e.g. Hänschen klein ('little Johnny'), Romantik pur ('pure romance'). If overlapping properties are 
crucial for the occurrence of cross-linguistic influence (CLI), overuse of prenominal placement in the French of German-French bilinguals is to be expected.

Developmental studies on bilingual children acquiring a Germanic and a Romance language simultaneously show that adjectives tend to be used prenominally in the Germanic language and pre- or postnominally in the Romance language. However, placement errors occur more often and for a longer period of time as compared to monolinguals (Bernardini, 2003; Nicoladis, 2006; Rizzi et al., 20I2). Nicoladis (2006) found that English-French bilinguals (ages 3;3 and 5;I) overgeneralised the postnominal order in French, contrary to the assumption that overlap is crucial for CLI to occur. Rizzi et al. (2OI2) showed for German-French bilingual children (aged I;6 to 5;4) that adjective placement was incorrect I $6.8 \%$ of the time and with a similar frequency in prenominal $(60 / 922=6.5 \%)$ and postnominal positions $(8 /$ I $35=5.9 \%)$. To our knowledge, there are no published studies on adjective placement involving adult 2 Lis.

\subsection{Gender}

French has masculine and feminine gender (e.g. le $e_{\mathrm{M}}$ soleil $_{\mathrm{M}}$ vs. $l a_{\mathrm{F}}$ lune $e_{\mathrm{F}}$, which is assigned to nouns in the lexicon. Assignment rules can be based on semantic properties (e.g. nouns denoting females are feminine), morphological properties (e.g. nouns ending in -ment are masculine, nouns in -elle are feminine) or phonological properties (e.g. nouns ending in nasal vowels tend to be masculine, nouns ending in $/ \mathrm{z} /$ tend to be feminine). Rules are probabilistic, i.e. reliable to different degrees, and for all rules there are exceptions (cf. Ayoun, 20Io; Corbett, I99I; Lyster, 2006; Tucker, Lambert and Rigault, I977 for overviews and discussion). Furthermore, semantic and formal (i.e. morphological and phonological) rules may clash (e.g., the noun laideron is masculine but refers to a female). Determiners, attributive adjectives and predicative adjectives receive gender through syntactic agreement, e.g. $l e_{\mathrm{M}}$ chat $_{\mathrm{M}}$ blanc $_{\mathrm{M}}$ vs. la $_{\mathrm{F}}$ maison $_{\mathrm{F}}$ blanche $_{\mathrm{F}}$.

German distinguishes feminine, masculine and neuter gender. Like French, German has semantic and formal assignment rules, but the rules in the two languages differ. Therefore, translation equivalents do not necessarily have the same gender (e.g. Fr. le $e_{\mathrm{M}}$ fauteuil $_{\mathrm{M}}-$ Ge. der Sessel $_{\mathrm{M}}$, but la $_{\mathrm{F}}$ chaise $_{\mathrm{F}}-$ Ge. der $\mathrm{M}$ $S t u h l_{\mathrm{M}}$ ). German also shows agreement on determiners and adjectives, but, unlike in French, adjectives in predicate position are not marked for agreement $\left(\right.$ Der $_{\mathrm{M}}$ Kater $_{M}$ ist schwarz 'The (male) cat is black.' vs. Die $e_{F}$ Katze $e_{F}$ ist schwarz. 'The (female) cat is black.'). Thus, German-French bilingual know another gender system. Nevertheless, in order to mark gender in French correctly, they have to learn the rules for agreement and assignment as well as the exceptions to these rules independently from German.

French gender, both assignment and agreement, is acquired effortless and relatively early, i.e. before age 3; (Karmiloff-Smith, I979), although agreement with certain adjective forms may be delayed (Royle and Valois, 20Io). In general, bilingual children have no problems acquiring gender either (Müller, I990, I999; 
Granfeldt, 2005), except when French constitutes the weaker language and develops very slowly (Kupisch, Müller and Cantone, 2002), or if it is acquired as an early second language (Granfeldt et al., 2007; Meisel, 2009). Gender can be subject to attrition, even if the contact language has gender (Håkansson, I995; Polinsky, 2008; Montrul, Foote and Perpinán, 2008).

\subsection{Article use in generic subject DPs}

Subject nominals in French require a determiner in order to be grammatical (5a). Noun phrases with a definite article are semantically ambiguous. When the noun is plural or mass, reference can be specific or generic, as in $(5 b)$.

(5) a. *Tournesols sont jaunes.

b. Les tournesols sont jaunes. (generic, specific)

'(The) Sunflowers are yellow.'

In the absence of cues forcing one of the two readings, speakers of Romance languages have been shown to favor the generic reading (see Pérez-Leroux, Munn, Schmitt and DeIrish, 2004 for Spanish; Kupisch and Pierantozzi, 20 Io for Italian).

Standard German uses bare nouns (henceforth NPs) for generic reference, if the noun is plural or mass (6a), while the definite article is associated with specific reference $(6 \mathrm{~b}){ }^{6}$

a. Sonnenblumen sind gelb. (generic)

b. Die Sonnenblumen sind gelb. (specific, ?generic) '(The) Sunflowers are yellow.'

Unlike German, French has indefinite plural and partitive articles (i.e. $d e s, d u$ and de l'), whose distribution is determined by contextual semantic factors. In a subject noun phrase, they are felicitous with a partitive reading expressing a contrast. For example, the DP in (7) refers to an indefinite subset of basketball-players. The sentence is felicitous because it sets a contrast to the general assumption that basketball-players are tall. Replacement of the adjective by 'tall' results in a generic reading, and des becomes inappropriate (7b).

(7) a. Des basketteurs sont petits.

of.the basketball-players are small (from Galmiche, I986: 58)

b. Les/(*des) basketteurs sont grands. the/(of.the) basketball-players are tall

For the expression of generic reference in French, learners of French need to know that the determiner cannot be omitted and that it must be a definite article. Influence from German predicts overuse of bare NPs and an inclination to interpret definite nominals as specific.

${ }^{6}$ For some speakers, definite marked nominals are also acceptable with generic reference, but unlike in French, bare NPs remain the default. 
In language acquisition, Spanish-learning preschool children prefer the generic reading of plural definite DPs $80-95 \%$ of the time, even if the context also allows for a specific reading (Pérez-Leroux et al., 2004). Bilingual children (simultaneous and successive) show CLI. In Italian, English-Italian children (age 6-Io years) corrected sentences with ungrammatical bare NPs less often than monolingual (child and adult) speakers of Italian, and bilingual children growing up in Italy outperformed their counterparts in the UK (Serratrice, Sorace, Filiaci and Baldo, 2009). GermanItalian bilingual children (ages 6-Io years) are less inclined to interpret definite DPs in Italian as generic ( $50 \%$ of all cases) than monolingual Italian children $(\sim 70 \%$ of all cases) (Kupisch and Pierantozzi, 20Iо). Adult heritage speakers of Spanish and Italian, bilingual with a Germanic language, have more problems than monolingual or majority speakers of these languages in correcting ungrammatical bare NPs, and they are less likely to interpret definite plural DPs as generic (Montrul and Ionin, 2010; Kupisch, 2012).

\subsection{Prepositions}

Prepositions are the border between lexical and functional elements. Functional, i.e. closed-class items, are generally characterised as being phonologically and morphologically dependent, unable to receive stress, permitting only one type of complement (typically IP, VP, NP), from which they cannot be separated, and lacking descriptive, i.e. lexical, content (Abney, I987: 43-44). In fact, none of these 5 characteristics holds for the entire class of prepositions. On the other hand, the criterion of having lexical content - most commonly cited when prepositions are classified as lexical - does not hold exclusively either, because some prepositions have undergone grammaticalization from lexical to functional items (Gabriel, 2002). We assume here that prepositions can be either functional or lexical, although membership in either group is not always clear-cut.

Both functional and lexical prepositions express relations between situations, times and directions, but the semantic relations expressed by functional prepositions are fewer in number and they are linked to the argument structure of the verb, while the semantic relation expressed by lexical prepositions has to be analysed for each individual context in which a preposition is used. Prepositions are challenging in acquisition because they are pluri-functional. They are even more challenging for bilingual learners because their functions across languages may overlap partially. To give an example of lexical prepositions, German auf 'on' translates into French sur. However, the expression auf eine Schule gehen (literally: go on a school) translates into aller à or dans une école but not * sur une école. The use of functional prepositions also differs across languages. For example, direction, as expressed by the verb 'give', requires the preposition $a ̀$ in French (e.g. donner $q c$ à qqn), while being expressed

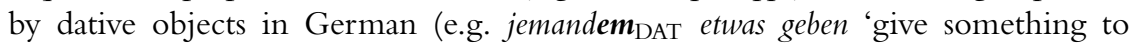
someone'). However, not all verbs requiring dative objects in German require à in French. For example, the German verb helfen 'help' requires a dative object 
(jemandem ${ }_{\mathrm{DAT}}$ helfen 'help someone'), but unlike donner, the French equivalent aider requires no preposition (aider $q q n$ ).

In $\mathrm{L}_{\mathrm{I}}$ acquisition research, supporters of the view that there is an initial stage without functional categories predict that lexical prepositions appear before functional ones (Stenzel, I994). Contrary to these assumptions, children acquiring French use functional prepositions ( $\grave{a}$ and $d e$ ) earlier and more frequently than lexical prepositions (Kochan, Morgenstern, Rossi and Sekali, 2007; Sekali and Morgenstern, 2009). For L2 acquisition, it is assumed that functional prepositions are more challenging than lexical prepositions (Wei, 2000; Steinhauer, 2006) and that the acquisition task differs for the two types. According to Grünewald (I995: 46), learners may store lexical prepositions as separate entries, while functional prepositions are stored together with their 'minimal contexts', which include information about their syntactic properties and their argument structure in addition to their lexical properties. In short, the general assumption in LI $_{\mathrm{I}}$ and L2 research appears to be that functional prepositions are more vulnerable than lexical ones.

\subsection{Global foreign accent}

By global foreign accent we refer to a foreign accent perceived by a monolingual speaker of a language, which results from certain phonetic and/or phonological properties (segmental or suprasegmental), and which deviates from the accent associated with monolingual speakers. The morpho-syntax of a speaker who sounds foreign may be entirely native-like.

French differs from German on the segmental and suprasegmental level. The most prominent difference on the segmental level is the existence of nasal vowels in French. Other differences include the contrast between / $/$ / and $/ a /$ and the existence of the liquid /n/ (both absent in German). Pronunciation also depends on the phono-syntactic context. For example, in word-initial position, /s/ tends to be realized as [s] in French but as [z] in German (e.g. German /zosə/vs. French /sos/ 'sauce'). Word-final /r/ tends to be realized in French, but vocalized in Standard German (e.g. cour [kus] 'lesson' vs. Kur / kup/ 'treatment'). Differences on the suprasegmental level include the phenomena of liaison, enchainement and e-caduc in French. Finally, French is a syllable-timed language and has a dynamic accent, in which duration and frequency are more important than intensity. German, on the other hand, is a stress-timed language with stressed syllables being more intense. On the phonetic level, the most frequently discussed difference between German and French is voice onset time (see below).

It is generally said that the phonetic and phonological properties of a language are acquired relatively early in life and that the earlier one is exposed to a language the less likely one's speech in this language will be accented (Moyer, I999: 8284; Piske, MacKay and Flege, 200 I, Jesney, 2004; Abrahamson and Hyltenstam, 2009 for overviews and relevant research). If this is correct, simultaneous bilinguals should have a relatively authentic accent in their two languages. On the other hand, 
there is evidence that at least the Li phonetic system retains some plasticity later in life. Specifically, adults who have lived in a country where the L 2 is the majority language for many years were shown to produce LI sounds with values differing from those of Li monolinguals, having adopted characteristics of the corresponding L2 sounds (Major, I992).

\subsection{Voice Onset Time}

Voice onset time (VOT) is the most salient cue to differentiate the language specific realizations of voiced $(/ \mathrm{b}, \mathrm{d}, \mathrm{g} /)$ and voiceless $(/ \mathrm{p}, \mathrm{t}, \mathrm{k} /)$ plosives. It refers to the time interval between 'the release of the stop' and 'the onset of glottal vibration, that is, voicing' (Lisker and Abramson, I964: 389). According to Lisker and Abramson (I964), there exist three different types of VOT: (i) 'voicing lead' (voicing starts before the release, resulting in voiced, unaspirated stops), (ii) 'short voicing lag' (voicing begins shortly after the release, resulting in voiceless, unaspirated stops), (iii) 'long voicing lag' (voicing starts a certain time after the release, resulting in voiceless, aspirated stops).

French distinguishes (i) voicing lead with negative VOTs, as instantiated by the voiced stops /b, d, g/, and (ii) short voicing lag, as for the voiceless stops /p, t, k/ with VOT values under 35 ms (Fischer-Jørgensen, I972; Laeufer, I996; Abdelli-Beruh, 2004). In German voiced stops fall in category (ii), while voiceless stops fall in category (iii) with VOT values longer than $40 \mathrm{~ms}$ (Fischer-Jørgensen, I976; Haag, I979). If speakers of French are influenced by German, their phonetic categories might change in direction of the dominant language with VOTs that are relatively long compared to those of monolingual French speakers, as proposed by the Speech Learning Model (Flege, I995).

Monolingual children acquire the distinction between short and long lag VOT by the age of 2;0-2;6 (Kewley-Port and Preston, I974; Macken and Barton, I979; Davis, I995; Kehoe et al., 2004), normally after producing the first words (StoelGammon, I985). The contrast between lead versus short lag VOT, present in French, Spanish or Italian, is only acquired after age 3 ; in some cases only after age 5, due to the difficulty to produce lead voicing (see Allen, I985 for French; Macken and Barton, I980 for Spanish and Bortolini; Zmarich, Fior and Bonifacio, I995 for Italian).

Studies on 2 Lis learning languages with different contrasts (e.g. lead vs short lag VOT in one language and short vs long lag VOT in the other) indicate that 2Lis do not differ from monolinguals in terms of quality (i.e. realizing the relevant contrasts in each of their languages), but sometimes in terms of quantity (i.e. rate of acquisition). The VOTs of four German-Spanish bilinguals studied by Kehoe et al. (2004) patterned with those of monolinguals in Spanish, but in German two of the children had not acquired the German contrast after age 3;0. The English-Spanish bilingual (aged I;7-2;3) studied by Deuchar and Clark (1996) acquired the contrast in English at age 2;3 and started distinguishing the Spanish stops just like monolingual children. Fabiano-Smith and Bunta (2OI2) analyzed 
the $/ \mathrm{p} /$ and $/ \mathrm{k} /$ productions of 8 Spanish-English bilinguals (ages 3;0-4;0). The bilinguals did not differ from age-matched monolinguals in their Spanish VOT, but their English VOT differed significantly from that of their monolingual peers, suggesting influence from Spanish (more visible on the labial than the velar stops). Watson (I990) showed that the VOT development of I 5 English-French bilingual children (ages 6, 8 and Io) was similar to that of age-matched monolinguals in both languages, indicating that VOT acquisition can, but need not be delayed in $2 \mathrm{LI}_{\mathrm{I}}$ acquisition.

For adult simultaneous 2Lis in Canada (French-English), Sundara et al. (2006) found VOT values for / $\mathrm{t} /$ similar to those of monolinguals in both English and French. Their participants, unlike those investigated here, lived in a bilingual environment in Canada and used both languages 'consistently within the home and the work context' (Sundara et al., 2006:Ior). Mac-Leod and Stoel-Gammon (2009; 20IO) investigated the VOTs of labial and coronal stops in 8 adult early French-English bilinguals (AoA before age 4;0). Again, bilinguals did not differ from monolingual speakers of French and English in their production of voiceless stops. Even sequential bilinguals (AoA 8-I2) in Canada were found to pattern with monolinguals (Mac-Leod and Stoel-Gammon, 20I0). Contrary to these studies, Fowler, Sramko, Ostry, Rowland and Hallé (2008) showed CLI in Is adult simultaneous bilingual speakers (French-English in Canada). For all three plosives these speakers differed significantly from the monolingual average in French; deviances in English were not significant (Fowler at al., 2008: 658).

Experiments in L2-acquisiton (Flege, I984; Flege and Eefting, I987), LI-attrition (Major, I987) and foreign accent imitation (Flege and Hammond, I982; Neuhauser, $20 \mathrm{I}$ ) suggest that VOT is correlated with degree of foreign accent.

\section{DATA AND METHODS}

\subsection{Participants}

Data come from 2I German-French bilinguals (2Lis) who had grown up in binational families but who differ in terms of their predominant country of residence during childhood and adolescence. All participants reported that their parents followed the one person - one language principle, i.e. each of them used their native language with their child, either German or French, although a few also admitted that their parents started using one language inconsistently at some point in their development. At the time of testing, participants were between the ages of 20 and 42 years (mean age 30 years). They were all tested in Germany.

We divided them into two groups depending on whether they spent most of their childhood and adolescence in France or not. We used I9 years as a cut-off point because the majority of our participants finished school at this age. ${ }^{7}$

7 Another option would have been to divide the subjects according to overall length of residence in Germany and France, which would have resulted in a slightly different 
Ten 2Lis spent the first I9 years of their lives predominantly in a French-speaking country. Seven of them had only visited Germany for vacation. The remaining three have spent several years in Germany ${ }^{8}$. Some attended a bilingual school $(n=2)$ or had additional instruction in German $(n=4)$. At the time of testing, these speakers had been living in Germany for between 4 months and 2 I years (mean 9.3 years). All but one speaker were fully immersed in the German society; during their daily lives they interacted mostly in German, while continuing to be part of a French-speaking community. Most speakers felt more comfortable using French than German $(n=5)$, or equally comfortable using both languages $(n=4)$. Only one person claimed that she preferred to speak German.

The other eleven 2 Lis spent the first ig years of their lives predominantly in Germany and, except for three speakers ${ }^{9}$, traveled to French-speaking countries only for vacations. Most of them $(n=8)$ attended a French or a bilingual school for some years, and their parents used their respective languages consistently. After the age of I9, these speakers had spent at most is months in a French-speaking country. Language use at the time of testing varied a lot, ranging between speakers who used French once per week $(n=I)$ and speakers who were part of a French-speaking community and used French as much as they use German $(n=2)$. Most 2 L Is were intermediate cases, using French regularly — albeit less often than German — in the context of family, education or work. Most $(n=$ Io) felt more comfortable using German.

For a first impression of the 2Lis' language skills in their two languages, we examined their performance in a written cloze test in both languages. The French test was made available to us by Annie Tremblay (Tremblay, 20I I); the German one was created by the authors. The two texts were similar in terms of lexical content and degree of difficulty. Both contained 45 gaps and tested lexical and morpho-syntactic knowledge.

Generally, the 2Liers who grew up in France performed better in the French cloze test, while those who grew up in Germany performed better in the German cloze test (see Table I). Only two speakers, one in each group, performed equally well in both languages. Both had been residents of German- and French-speaking countries for many years (see footnotes 7 and 8). Based on these results, we made the preliminary assumption that the 2 Lis who grew up in France speak French as their stronger (first) language, while those who grew up in Germany speak French as their weaker (first) language, although we are aware that their written language skills need not coincide with other language skills. Table I provides an overview of the participants.

grouping. We decided against the latter solution, as we suspected the language of the childhood environment to be more crucial for degree of native-likeness than the language environment during adulthood.

8 They spent I, 3 and between 8 and 9 years, respectively, in Germany.

9 The first spent time in Guadeloupe (ages 5-IO); the second in France (ages 5-IO and I7-I9); and the third in France, Morocco and Cameroun (9 years overall). 
Table I. Overview of participants

\begin{tabular}{lll}
\hline \hline & $\begin{array}{l}\text { 2Lis who grew up } \\
\text { predominantly in } \\
\text { France }\end{array}$ & $\begin{array}{l}\text { 2Lis who grew up } \\
\text { predominantly in } \\
\text { Germany }\end{array}$ \\
\hline $\begin{array}{l}\text { Number } \\
\begin{array}{c}\text { Time spent in Germany after } \\
\text { age I9 (months/age-I9years) }\end{array}\end{array}$ & $51 \%$ & I I \\
$\begin{array}{l}\text { Cloze test in French (accuracy } \\
\text { in \%) }\end{array}$ & $89 \%$ (range 76-I00\%) & $72.3 \%$ (range 42-87\%) \\
$\begin{array}{l}\text { Cloze test in German (accuracy } \\
\text { in \%) }\end{array}$ & $80 \%$ (range 29-I00\%) & $89 \%$ (range 67-98\%) \\
\hline \hline
\end{tabular}

The data collection reported in the following took place either at the participants' homes, in a quiet room at a research center, university, or library. Interviews and tests were conducted by native speakers of French, and French was the only language of interaction.

\subsection{Acceptability Judgment Task (AJT)}

We tested adjective placement, gender assignment and agreement and article use in generic utterances by means of an acceptability judgement task (AJT). It included a total of I 54 stimuli, of which 32 were fillers. ${ }^{10}$ The sentences were intensively piloted with monolingual native speakers of French ${ }^{11}$ based on a paper-pencil version. All stimuli were previously recorded by a female monolingual native speaker of French from France.

The participants, wearing headphones with an integrated microphone, completed the experiment on a computer. Instructions were in French and there was a training phase consisting of three examples. In the experiment, participants read and heard a test sentence. They were asked to orally repeat the test sentence if they thought it sounded acceptable and to orally correct it if they judged it faulty. Response time was limited to three times the length of the previously recorded test sentence, and responses were automatically recorded, provided they were within the given time frame. The order in which stimuli were presented was automatically randomised.

Test items. Among the I 54 items, 46 tested adjective placement, 36 tested gender assignment and agreement, and 40 tested article use in specific and generic DPs. For each phenomenon, $50 \%$ of the stimuli were ungrammatical or infelicitous.

10 We did not use a higher number of fillers because the test was relatively long. Items testing one phenomenon could be taken as fillers for another phenomenon.

11 Someone was considered monolingual, if only one language was used at home during childhood, and if this language was also the only language of instruction at school. 
Among the 46 items testing adjective placement, 50\% appeared with prenominal adjectives and $50 \%$ with postnominal ones (cf. $7 \mathrm{a}$ vs. $7 \mathrm{~b}$ ). There were different types of adjectives (cf. examples I-4).

(7) a. J'aime bien acheter des vêtements. Aujourd'hui, j'ai acheté une jupe verte.

I love much buy.INF of.the clothes today I have bought a skirt green

'I like to buy clothes. Today I bought a green skirt.'

b. *Pierre est très petit. C'est pourquoi sa femme lui a offert une courte cravate.

Pierre is very small it is why his wife him has given a short tie

The 36 sentences testing gender assignment and agreement contained subject DPs with definite articles and adjectives in the singular. The latter were balanced for gender ( $50 \%$ masculine and $50 \%$ feminine). Each noun appeared twice in the test: once with an attributive adjective and once with a predicative adjective (cf. $8 \mathrm{a}$ vs. $8 b)$.

(8) a. ${ }^{*} e_{\mathrm{M}} \quad$ poule $_{\mathrm{F}} \quad$ astucieux $_{\mathrm{M}}$ sait voler. the chicken cunning knows fly.INF

b. ${ }^{*} L e_{\mathrm{M}}$ poule pui $_{\mathrm{F}}$ a trouvé les graines est astucieux $\boldsymbol{M}_{\mathrm{M}}$. the chicken who has found the grains is cunning

Gender marking on predicative adjectives was expected to be more challenging due to the longer distance between the noun and the adjective (involving higher processing costs) and because predicative adjectives are not marked for gender in German. In ungrammatical sentences, both the article and the adjective were marked with the wrong gender, as in (8).

The 40 sentences testing article use contained subject DPs in which the definite article was present (appropriate definite), replaced by the indefinite article des (inappropriate indefinite), or absent (inappropriate omission). All sentences were preceded by a context cuing a specific or generic reading. The contexts cuing the generic reading tested whether participants encountered difficulties in contexts where German and French are different, and whether these problems were of syntactic or semantic nature. The contexts cuing the specific reading controlled whether participants had problems using the definite article in contexts where German and French pattern alike.

In this paper, we focus on the conditions with contexts sentences cuing the generic interpretation $(\mathrm{n}=32)$. The context sentences, e.g. Animal lovers know that..., At school I have learnt that ..., reinforced the interpretation of the subsequent sentence as a general fact or statement. These were followed by three types of test sentences in which the correct response contains a definite subject DP. The type in (9a) illustrates a case where the subject DP is appropriate (thus requiring repetition), in (9b) the indefinite article should be replaced by a definite one, and in (9c) a definite article should be inserted. 
(9) a. Les chevaux sont herbivores. (appropriate definite) the horses are herbivores

b. Des lions vivent dans la savane. (inappropriate indefinite) of.the lions live in the savanna

c. Pommes de terre poussent dans la apples of earth sprout in the terre. (inappropriate omission) earth

Data analysis. As mentioned above, subjects were asked to provide a correction or a repetition depending on their judgement of the sentence. The corrections and repetitions were used to examine whether subjects are responding relevantly. For example, if the position of the noun and the adjective in une courte cravate was reversed, the correction counted as relevant, because it suggests sensitivity to adjective order. Corrections which fail to eliminate the relevant violations, such as un court cravate, where the gender of the DP has been changed, were treated as if no correction had been made.

\section{$4 \cdot 3$ Spontaneous data}

Data for the analysis of prepositions, global foreign accent and voice onset time was gathered in loosely pre-structured interviews with the aforementioned participants, lasting between 20 and 30 minutes. Since the procedure was very different for each of the three phenomena, we explain them separately.

Prepositions. We searched the entire interviews for prepositions, including the following categories:

(i) Lexical prepositions, including simple prepositions (sur 'on', pour 'for'), prepositionally used participles (pendant 'while', durant 'while'), composed prepositions referring to a single location (d'après 'according to', de derrière 'from behind'), and prepositions in adverbial positions (il était là avant 'he was there before'),

(ii) Functional prepositions $(\grave{a}, d e)$,

(iii) Complex prepositional phrases, e.g. à côté de 'next to', à partir de 'from', which constitute fixed expressions.

Prepositions were divided into native-like and incorrect uses. Use of prepositions which can be considered jargon was counted as native-like. We consulted nativespeakers from different regions in France (two from Toulouse, three from Paris and one from Nantes), aged between 22-54 years, in order to rule out that certain uses were classified as unacceptable due to regional variation or age.

We excluded the partitive article de, prefixes and prepositional elements within compounds (e.g. sous-entendre 'imply', sans-papiers 'illegal immigrant') and prepositions within fixed nominal expressions (e.g. coup de fil 'phone call'). In selfcorrections, the form produced at the end was included. Prepositions that were 
morphologically incorrect, e.g. in cases where preposition and article were fused, were counted as correct if they contained the correct preposition, as e.g. je pense au [à] l'Europe du sud 'I think of Southern Europe'.

Global foreign accent. Again, we used the naturalistic data, this time to create an experiment accessing whether the speakers' global accent sounded foreign. We excluded data from one speaker because the sound quality of the recording was insufficient. For the experiment, we added data from five monolingual Li speakers and five L2 speakers to set the borders for a continuum of accents: Clearly nativesounding speakers as one extreme (monolingual LI speakers) and L2 speakers as the other extreme. The L2 speakers were LI German late learners of French (age of onset after I I years) who performed at ceiling in morpho-syntactic tasks but were clearly-foreign sounding.

When preparing the experiment, we selected two passages from each speaker, one lasting I 5 seconds and one lasting 30 seconds $\left( \pm_{10} \%\right)$. The criterion for choosing the passages was that they contained no information on cultural background, no morpho-syntactic errors and no long hesitations or pauses. Most passages that were eventually selected contained a description of a book or a movie. The samples from the 20 speakers were semi-randomised, and two test versions were created.

Speech samples were rated by 23 adult monolingual (LI) speakers of French, living in Paris. Stimuli were presented to the raters over headphones with a PowerPoint presentation. There was a training period with two examples, one from a monolingual Li speaker, and one from a L2 speaker with a relatively strong foreign accent, to ensure that the raters understood the task. Raters were asked to judge the samples in four steps: (i) they heard a sample of is seconds and had to decide whether the speaker sounded foreign or native; (ii) they had to indicate how certain they were ('certain', 'semi-certain', or 'uncertain'). If a rater considered a speaker foreign-sounding, he was asked to explain which phonetic or phonological features he based his decision on. Raters were encouraged to repeat certain words or passages if they had problems using linguistic terminology. They subsequently heard another sample of the same speaker, this time for 30 seconds. After listening to the second sample, they had the chance to revise their judgements. They were told to count a regional accent as native.

Voice Onset Time (VOT). We measured VOT for /p, t, k/ in the spontaneous speech of a subgroup of the $2 \mathrm{LI}$ speakers, five with French as their dominant language and five with German as their dominant language. Only io participants were chosen because the analysis was very time consuming. The choice was based on the length of the interviews to obtain the highest possible number of items per speaker. The analysis was done with Praat (Boersma and Weenink, 20I2), and included all monosyllabic verbs, nouns and adjectives with initial plosives preceding a vowel in stressed position. An overall number of $\mathbf{4 9 4}$ words were analysed. ${ }^{12}$

12 The analysis was restricted to monosyllabic nouns, because it was geared towards a comparison of German and French. German and French show different stress patterns in multi-syllabic words (German mostly on the first syllable (trochaic) (Dohmas et al., 2008), 
Table 2. Accuracy with adjective placement

\begin{tabular}{lllll}
\hline \hline & Overall accuracy & $\begin{array}{l}\text { Syntax proper } \\
(\mathrm{N}=22)\end{array}$ & $\begin{array}{l}\text { Syntax-semantics } \\
(\mathrm{N}=\mathrm{I} 4)\end{array}$ & $\begin{array}{l}\text { Syntax-pragmatics } \\
(\mathrm{N}=\mathrm{I})\end{array}$ \\
\hline 2LI strong & $423 / 432(97.9 \%)$ & $206 / 2 \mathrm{IO}(98 . \mathrm{I} \%)$ & $94 / 96(97.9 \%)$ & I 23/I $26(97.6 \%)$ \\
2Li weak & $430 / 477(90 . \mathrm{I} \%)$ & $224 / 236(94.9 \%)$ & $79 / \mathrm{IO} 4(76.0 \%)$ & $\mathrm{I} 27 / \mathrm{I} 37(92.7 \%)$ \\
\hline \hline
\end{tabular}

\section{RESULTS}

\subsection{Adjective placement}

An ANOVA for adjective placement showed that the heritage speakers of French were less often target-like than 2Lis with French as the stronger language (see Table 2), $F($ I, I9), $p=0.006$. We divided test items into three groups depending on what kind of domain they involved (examples I-4). Adjectives that appear in the canonical postnominal order exclusively (jupe verte) were labeled as involving no interface ('syntax proper'). Adjectives in idiomatic expressions (chaudes larmes) and adjective-noun strings where the position of the adjective depends on the meaning of the noun it modifies (court instant) were labeled as 'syntax-semantics'. ${ }^{13}$ The third group, 'syntax-pragmatics', contained adjectives whose position depends on the meaning conveyed by the wider context (jeune mère), as in example (4). Table 2 shows the results.

MANOVA results indicate that language background has a significant effect on accuracy in adjective placement, $F(3, \mathrm{I} 7)=3.238, p<0.05, \eta^{2}=0.364$. Univariate ANOVAs were conducted as follow up test. ANOVA results indicate that the only significant difference between the groups was found in syntax-semantics adjective placement where the French strong bilinguals scored significantly higher than those bilinguals who grew up in Germany $F(\mathrm{I}, \mathrm{I} 9)=9.697, p=0.006$. No betweengroup difference was found for syntax-proper adjective placement, $F(\mathrm{I}, \mathrm{I} 9)=\mathrm{I} .778$, $p>0.05$ and syntax-pragmatics adjective placement, $F(\mathrm{I}, \mathrm{I} 9)=0 . \mathrm{II}$ I, $p>0.05$. In other words, $2 \mathrm{~L}$ Is with French as their stronger language have no problems with adjective placement, while 2 Lis with French as their weaker language do, but only if correct placement requires lexical or semantic knowledge.

\subsection{Gender}

Results were analysed for assignment and agreement separately. We took the article as an indicator of assignment. Agreement was established based on the article and the adjective. Nouns were included in the analysis of assignment only if both

French on the last tense vowel of a word (iambic) (Walker, I975). Two-syllable words ending in schwa were included because these are generally reduced in spoken French. The analysis also included vowel quality, but we will not report on that.

13 This group is not perfectly homogenous because, arguably, adjectives in idiomatic expressions must be stored as chunks in the mental lexicon, whereas adjective placement with adjectives like court could also be resolved on more general semantic knowledge. We grouped them together because both can be associated with the internal modules, no matter whether lexical or semantic knowledge is crucial. 
Table 3. Accuracy in gender assignment and agreement

\begin{tabular}{llll}
\hline \hline & assignment & $\begin{array}{l}\text { Agreement on attributive } \\
\text { adjectives }\end{array}$ & $\begin{array}{l}\text { Agreement on } \\
\text { predicative adjectives }\end{array}$ \\
\hline 2LI strong & I74/I77 (98\%) & I74/I75 $(99.9 \%)$ & I75/I $79(97.8 \%)$ \\
2LI weak & I50/I6I $(93.2 \%)$ & I68/I75 $(96 \%)$ & I63/I $74(93.7 \%)$ \\
\hline \hline
\end{tabular}

Table 4. Determiner syntax in generic contexts

\begin{tabular}{|c|c|c|c|}
\hline & $\begin{array}{l}\text { Article use with } \\
\text { stimulus sentences } \\
\text { containing definite } \\
\text { DP }(n=16)\end{array}$ & $\begin{array}{l}\text { Article use with } \\
\text { stimulus sentences } \\
\text { containing indefinite } \\
\text { DP }(n=8)\end{array}$ & $\begin{array}{l}\text { Article insertion } \\
\text { with stimuli } \\
\text { containing bare NPs } \\
(\mathrm{n}=8)\end{array}$ \\
\hline 251 & I58/I 58 (I00\%) & $79 / 79($ I00\%) & $80 / 80(100 \%)$ \\
\hline $2 \mathrm{LI} w$ & I73/I73 (100\%) & $86 / 86($ (о0о\%) & $73 / 76(96.1 \%)$ \\
\hline
\end{tabular}

occurrences of the same noun had been marked with the same gender. That is, inconsistent gender marking was taken to indicate that no particular gender has been assigned and the respective items were excluded. ${ }^{14}$ Agreement was coded by determining for each single item (including DPs with inconsistent assignment) whether the article was marked with the same gender as the adjective or not. Results are illustrated in Table 3 .

There was no significant difference between the two bilingual groups, neither for gender assignment, $F(\mathrm{I}, \mathrm{I} 7)=3.00 \mathrm{I}, p>0.05$, nor for gender agreement, $F(\mathrm{I}, \mathrm{I} 7)=3.468, p>0.05$. Neither of the groups showed a within-group effect for gender agreement on attributive vs. predicative adjectives, $F(\mathrm{I}, 2 \mathrm{O})=0.033$, $p>0.05$ for the heritage speakers of French; $F(\mathrm{I}$, I9) $=1.226, p>0.05$ for 2Lis with French as the stronger language. This means that neither the increased processing load for predicative adjectives nor CLI from German poses a challenge for bilinguals.

\subsection{Article use in generic subject DPs}

For the analysis of article use in the items with a generic context, we first analysed how often participants accepted the presence of a determiner or corrected subject nominals with missing determiners, regardless of the determiner's semantic correctness (determiner syntax), as shown in Table $4 .{ }^{15}$

A MANOVA comparing the two groups in the three domains, testing whether the two groups differ significantly and using the dependent variables 'group' and 'domain', yielded no significant difference, $F(\mathrm{I}, \mathrm{I} 8)=3.836, p>0.05$.

14 Twelve instances were excluded because of inconsistent assignment. Inclusion of DPs with inconsistent gender marking on the article would not bring about noticeable changes in accuracy because an equal number of DPs with correct and incorrect gender marking would be included.

15 In this and in the following analysis, one participant (2LI weak) was removed as an outlier, showing a deviation of more than $2.5 \mathrm{SD}$ from the mean. 
Table 5. Determiner semantics in generic contexts

\begin{tabular}{llll}
\hline \hline & $\begin{array}{l}\text { (i) Acceptance of } \\
\text { definite DPs }\end{array}$ & $\begin{array}{l}\text { (ii) Correction of } \\
\text { indefinite to definite DPs }\end{array}$ & $\begin{array}{l}\text { Correction of NPs } \\
\text { to definite DPs }\end{array}$ \\
\hline 2LI strong & I58/I58 (100\%) & $74 / 79(93.7 \%)^{16}$ & $80 / 80($ I00\%) \\
2LI weak & I7I/I73 $(98.8 \%)$ & $68 / 78(87.2 \%)$ & $72 / 76(94.7 \%)$ \\
\hline \hline
\end{tabular}

Next, we took a closer look at the items in which an article was used. In other, words, we did a semantic analysis on the same items as before, excluding the few cases in which inappropriate bare NPs have been accepted. We looked at (i) how often the definite article in the appropriate condition was accepted rather than changed to another article (e.g. des), (ii) how often an inappropriate indefinite article was changed to a definite article (i.e. des $\rightarrow$ les), and (iii) how often a bare NP was corrected to a definite marked DP (Table 5 ).

A MANOVA in which accuracy was compared by domain for the two groups, yielded no significant difference, $F(3, \mathrm{I} 6)=\mathrm{I} .2, p>0.05$.

In summary, there were no differences between the two groups, although the heritage speakers showed minor uncertainties in choosing the appropriate article.

\subsection{Prepositions}

Prepositions occurred with a similar frequency in both groups. The relative amount of functional and lexical prepositions and prepositions in idiomatic expressions was similar as well. The latter were least frequent (I $4 \%$, both groups), lexical prepositions were most frequent $(50 \%$ and $53 \%)$, functional ones ranging between these categories $(36 \%$ and $33 \%$ ) (values for $2 \mathrm{Lis}$ with French as their stronger language mentioned first). Prepositions were rarely used incorrectly. The few existing non-target like occurrences include mostly substitutions (IOa), some omissions (Iob) and very few insertions where no preposition is required (IOc) (examples simplified).

(Iо) a. ilya plein de médecins qui part en étranger...
there are many of doctors who leave to abroad...
b. ça c'est passé $\underline{\varnothing}$ un peu près comme ça.
that that's passed a bit close like that
c. $\ldots$ que j'apprenne un peux à à faire des
that I learn
intubations ou de mettre des perfusions.
catheters or to put of.the infusions

Prepositions in idiomatic expressions were used appropriately except by one heritage speaker of French. Table 6 provides an overview of the results. Differences

I6 We suspect that the comparatively low performance in correcting indefinite DPs was due to one particular item, which was ambiguous between a generic and an eventive reading. The latter would allow an indefinite DP. 
Table 6. Prepositions from the total of words, numbers and type of errors

\begin{tabular}{lrr}
\hline \hline & 2LI strong & 2LI weak \\
\hline Total no. of words & 25 I 52 & 22069 \\
Prepositions (\% from total of words) & $2367(9.4 \%)$ & 20 IO (9.5\%) \\
Inappropriate uses (\% from total of prepositions) & $9(0.4 \%)$ & $35(\mathrm{I} .7 \%)$ \\
Omissions & - & I I \\
Substitutions & 6 & I 5 \\
Insertions & 3 & 7 \\
\hline \hline
\end{tabular}

in the rate of errors between the two groups are minor, $F(\mathrm{I}, \mathrm{I} 7)=2.658, p>0.05$, as shown by an ANOVA.

Errors can be characterised further in terms of slips of the tongue, as in (I Ia) where ' $d$ is redundant, lexical selection errors (e.g. sur of dans), as in (IIb), and overuse of default prepositions, mostly $d e$, as in (IIC). Some lexical selection error may have been caused by transfer (e.g. I I b).

(II) a. en troisième d'année de licence de audiovisuel...
in third of year of permission of audiovisual
b. après j'ai fait le bac en Allemagne
after I have made the bac in Germany
aussi sur une école française.
also on a school French
c. je me rappelle bien $\ldots$ comment il voulait
I self remember well how he wanted
vraiment certainement de m'apprendre.
really certainly to me teach

\subsection{Global foreign accent}

Table 7 summarises the results of the accent rating experiment. The first row shows the number of times that raters judged individual speakers as foreign when hearing them for the first time. Each of the 20 speakers was judged 23 times, which results in 230 judgements for each group of 2 Lis. Note that the monolingual speakers in this task were deemed as 'native' only 92\% of the time (range: $83-100 \%$ ).

The second row of the table shows how often raters revised their judgements from considering a speaker 'native' to considering him a 'foreign' speaker, or vice versa, when listening to the same speaker for a second time. When raters revised their original judgements, they tended to do so from 'foreign' to 'native' when listing to a $2 \mathrm{LI}$ who grew up in France ( $9 / \mathrm{I} 4$ times), while tending to revise their judgements from 'native' to 'foreign' when listening to a heritage speaker of French $(23 / 26)$. Finally, the table indicates the raters' certainty when judging the data. An ANOVA shows that the heritage speakers of French were judged as native speakers of French significantly less often than those who grew up in a French speaking 
Table 7. Results of the foreign accent rating task (Average accent ratings, degree of certainty and number of revisions)

\begin{tabular}{lll}
\hline \hline & 2L I strong & 2L I weak \\
\hline Number of instances a speaker was judged as & $23 / 230$ & I I $8 / 230$ \\
'foreign' on first listening (I 5 seconds) & (I0\%) & $(5$ I $\%)$ \\
Total number of revisions on second listening & I $4 / 230$ & $26 / 230$ \\
$\quad(30$ seconds) & $(6.1 \%)$ & $($ I I.0\%) \\
Average degree of certainty during judgments & I.4 & I.7 \\
$\quad$ (I = certain, 3 $=$ uncertain) & & \\
\hline \hline
\end{tabular}

country, $F(\mathrm{I}, \mathrm{I} 8)=\mathrm{I} 5.696, p=0.002$. Since there was also variation among the speakers with French as stronger language, we looked at whether foreign accent correlated with their length of residence in Germany. There was no correlation between global foreign accent and residence in Germany in years, $r=$ o.II $2, p$ (one-tailed) $>0.05$.

\subsection{VOT}

Table 8 presents the results for VOT, comparing the values reported in the literature (Fischer-Jørgensen (1972), Laeufer (I996: 94)) for monolingual French speakers to values measured here for the 2 Lis.

The differences in absolute VOT between the two groups of bilinguals and monolingual French speakers is significant, $\mathrm{F}(2, \mathrm{I} 7)=4.987, p<0.05$. Bonferroni post-hoc tests showed that neither the French strong group and the monolingual native speakers $(p>0.05)$ nor the two bilingual groups $(p>0.05)$ differed in their VOT production. Only the French heritage speakers and the monolinguals differed significantly in their VOT productions $(p<0.05)$.

A multivariate analysis of variance revealed that language background significantly affects the combined dependent variable of place of articulation [Wilk's $\left.\Lambda=0.34 \mathrm{I}, F(6,30)=3.558, p=0.009, \eta^{2}=0.4 \mathrm{I} 6\right]$. Univariate ANOVA and Bonferroni post hoc tests were conducted as follow-up tests. ANOVA results indicate that VOT in coronals $[F(2,17)=4.842, \mathrm{p}<0.05]$ and dorsals $[F(2$, I 7) $=4.842, p<0.05$ significantly differ between groups. No such difference was found for labials, $F(2,17)=\mathrm{I} .027, p>0.05$. Bonferroni post hoc results showed that only the heritage speakers and the monolinguals differed in their VOT for dorsals $[p<0.05]$ and coronals $[p<0.05]$.

\section{DISCUSSION AND CONCLUSIONS}

Our study set out to explore whether there are different acquisition outcomes depending on whether French is acquired in a minority-language context or a majority-language context. We found that the 2Lis who were born in France and spent most of their childhood and adolescence in francophone countries performed 
Table 8. Mean VOT values (in ms) for French 2 L1s and monolinguals

\begin{tabular}{llll}
\hline \hline & $/ \mathrm{p} /$ & $/ \mathrm{t} /$ & $/ \mathrm{k} /$ \\
\hline mean VOT in LI speakers & I6.0 & $\mathbf{2 0 . 2}$ & $\mathbf{3 I . 5}$ \\
Min VOT (ms) & I0.7 & I 4.9 & 25.8 \\
Max VOT (ms) & $3 \mathrm{I} .5$ & 35 & 46.3 \\
No. of items & $28 \mathrm{I}$ & $3 \mathrm{I} 2$ & 290 \\
2LI strong French & I2.9 & $\mathbf{2 6 . 0}$ & $\mathbf{3 9 . 2}$ \\
Min VOT (ms) & I0.5 & $2 \mathrm{I} .3$ & 33.4 \\
Max VOT (ms) & I5.7 & $3 \mathrm{I} .8$ & 46.4 \\
No. of items & I IO & 48 & 53 \\
2LI weak French & I6.I & $\mathbf{2 8 . 8}$ & $\mathbf{4 3 . 6}$ \\
Min VOT (ms) & I I.6 & I7.2 & 23.9 \\
Max VOT (ms) & 23.9 & 39.6 & 59.2 \\
No. of items & I 5I & 73 & 59 \\
\hline \hline
\end{tabular}

more native-like than $2 \mathrm{~L}$ Is who grew up as heritage speakers of French in Germany. However, differences were restricted to particular domains, which brings us to the second question, namely whether particular domains are more vulnerable to CLI, incomplete acquisition or attrition than others. Since $2 \mathrm{~L}$ Is with French as their stronger language showed ceiling performance (above $95 \%$ accuracy) in all measures but pronunciation (but see footnote 13 ), we assume that absence of a significant difference between the two groups of 2 Lis suggests that heritage speakers of French performed like native speakers.

Overall, heritage speakers performed native-like in several morpho-syntactic domains, similar to $2 \mathrm{~L}$ Is with French as their stronger language. This distinguishes our study from previous studies on heritage speakers (e.g. Montrul, 2008; Polinsky, 1997, Benmamoun, Montrul and Polinsky, forthcoming). Differences between the two groups of bilinguals were not significant in gender assignment and gender agreement, article use in generic utterances and use of prepositions. Differences in adjective placement were limited to cases involving lexical and semantic knowledge. By contrast, the heritage speakers of French were judged native significantly less often than the 2Lis with French as their stronger language. While the two groups' overall VOT production did not differ significantly, the heritage speakers differed significantly from monolinguals in their VOT for coronal and dorsal plosives. Table 9 summarises the results.

At first sight, our data obtained from different experimental paradigms does not support the view that heritage speakers perform relatively better in uncontrolled data collection situations (e.g. Montrul, 2009). In our study, the reversed pattern was observed: the least controlled data brought out the strongest deviation from monolingual norms. However, Montrul's findings were based on morphosyntactic phenomena. In the present study, we did not investigate morpho-syntactic phenomena in naturalistic speech, but it is likely that both groups of bilinguals would have shown no difficulties here. After all, it is easier to monitor the use of certain grammatical constructions or lexical items than the accent, because for the former 
Table 9. Summary of significant differences between the two groups of $2 L_{1}$ S

\begin{tabular}{|c|c|}
\hline & Significant differences between the two groups \\
\hline $\begin{array}{l}\text { Adjective } \\
\text { placement }\end{array}$ & $\begin{array}{l}\text { Yes (but only when lexical and semantic knowledge was } \\
\text { involved) }\end{array}$ \\
\hline Gender & 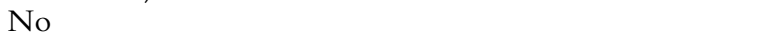 \\
\hline $\begin{array}{l}\text { Article use in } \\
\text { generic contexts }\end{array}$ & No \\
\hline Use of prepositions & No \\
\hline $\begin{array}{l}\text { Global Foreign } \\
\text { Accent }\end{array}$ & Yes \\
\hline Voice Onset Time & $\begin{array}{l}\text { No (but heritage speakers differed from monolinguals with } \\
\text { respect to } / \mathrm{t} / \text { and } / \mathrm{k} / \text { ) }\end{array}$ \\
\hline
\end{tabular}

there are alternative ways of expression, while there are no (target-like) alternatives to using the phonemes, their phonetic realisations, or the intonation of a language.

Our results also shed different light on the assumption that heritage speakers may be subject to incomplete acquisition, as suggested by Polinsky (I997) and Montrul (2008). According to Montrul, 'incomplete acquisition is also a possible result but certainly not the only one- of language acquisition by children and adults in a dual language environment.' (Montrul, 2008: 6, emphasis ours).

In fact, the heritage speakers in this study show a lot of evidence for complete acquisition. Even though we have not included a control group of monolingual speakers in all experiments, we have made sure by consultation and pre-testing with native speakers that our experiments and analyses were based on what monolingual native speakers accept as native-like behaviour. The only domains that turned out to be vulnerable in bilinguals were lexico-semantic properties and pronunciation. Since the acquisition of the lexicon is a process that continues over a lifespan, and since even monolingual speakers differ in terms of their lexical inventories, such properties can hardly be taken as evidence for incomplete acquisition in bilinguals.

On the other hand, when we investigated the heritage speakers' pronunciation, there was no doubt that heritage speakers of French were taken to be foreign speakers of the language more often than they were deemed native. Nevertheless, it remains debatable whether this makes their grammar incomplete. In order for a grammar to count as incomplete, this grammar should generate unsystematic rather than systematic deviances from a monolingual norm (Sorace, I993). Our heritage speakers have always had dominant exposure to German. Some aspects of their phonetic and phonological systems in French seem to be influenced by the corresponding German systems, as suggested by the fact that their VOT realisations for $/ \mathrm{t} /$ and $/ \mathrm{k} /$ were significantly longer, i.e. more German-like, than those of monolinguals. This observation is consistent with the assumption that their French and German were acquired distinctly, but that there was subsequent attrition with the French sounds assimilating to their German counterparts. It is also consistent with the view that speakers have developed compromised values in French, as suggested by Flege's (I995) Speech Learning Model. Regardless of which of the 
two scenarios is correct, this did not make their linguistic systems incomplete, but rather divergent from those of bilinguals who grew up in France.

The final point we addressed was whether simultaneous bilinguals are particularly vulnerable to language attrition. Since 2 Lis who grew up in France but moved to Germany as adults showed ceiling performance in almost all domains, such a conclusion seems unjustified. Only in the foreign accent task did speakers in this group show more variation. However, no speaker was consistently deemed foreign, and there was no correlation of the degree of foreign accent and length of residence in Germany. Moreover, this group did not differ from monolinguals in their VOT productions. This suggests that even if the $2 \mathrm{~L}$ Is who moved to Germany as adults are sometimes perceived as foreign by some raters, it is rather unlikely that there has been a permanent loss of certain phonetic or phonological properties.

Address for correspondence:

Tanja Kupisch

Italian Studies

Centre for Languages and Literature

Lund University

Helgonabacken 12

SE-223 62 Lund

Sweden

e-mail:tanja.kupisch@uni-hamburg.de

\section{REFERENCES}

Abdelli-Beruh, N. B. (2004). The stop voicing contrast in French sentences: Contextual sensitivity of vowel duration, closure duration, voice onset time, stop release and closure voicing. Phonetica, 6I: 20I-2 I9.

Abney, S. (1987). The English noun phrase in its sentential aspect. PhD dissertation, MIT.

Abrahamsson, N. and Hyltenstam, K. (2009). Age of onset and nativelikeness in L2: Listener perception versus linguistic scrutiny. Language Learning, 59.2: 249306.

Allen, G. D. (1985). How the young French child avoids the pre-voicing problem for word-initial voiced stops. Journal of Child Language, I2: 37-46.

Andersen, R. (1982). Determining the linguistic attributes of language attrition. In: R. Lambert and B. Freed (eds), The Loss of Language Skills. Rowley, MA: Newbury House, pp. 83-I I 8.

Ayoun, D. (20I0). Corpus data: shedding the light on French grammatical gender. . or not. Eurosla Yearbook, iо.I: I I9-I4I.

Benmamoun, E., Montrul, S. and Polinsky, M. (forthcoming). Heritage languages and their speakers: Opportunities and challenges for linguistics. Theoretical Linguistics.

Bernardini, P. (2003). Child and adult acquisition of word order in the Italian DP. In: N. Müller (ed.), (In)vulnerable Domains in Multilingualism. Amsterdam: Benjamins, pp. $4 \mathrm{I}-8 \mathrm{I}$. 
Bialystok, E. and Ryan, E. (1985). A metacognitive framework for the development of first and second language skills. In: D. L. Forrester-Pressley, G. MacKinnon and T. Walker (eds), Metacognition, Cognition and Human Performance, Orlando FL: Academic Press, pp. 207-252.

Birdsong, D. (1989). Metalinguistic Performance and Interlinguistic Competence. Berlin: Springer.

Boersma, P. and Weenink, D. (I992-2012). Praat: Doing phonetics by computer. $<$ http://www.praat.org/>.

Bortolini, U., Zmarich, C., Fior, R. and Bonifacio, S. (1995). Word-initial voicing in the productions of stops in normal and preterm Italian infants. International Journal of Pediatric Otorhinolaryngology, 3 I: I9I-206.

Bullock, B. and Gerfen, C. (2004). Frenchville French: A case study in phonological attrition. International Journal of Bilingualism, 8.3:303-320.

Corbett, G. (1991). Gender. Cambridge: Cambridge University Press.

Davis, K. (1995). Phonetic and phonological contrasts in the acquisition of voicing: voice onset time production in Hindi and English. Journal of Child Language, 22: $275-305$.

De Houwer, A. (I995). Bilingual language acquisition. In: P. Fletcher and B. MacWhinney (eds), Handbook of Child Language. Oxford: Blackwell, pp. 219-250.

Deuchar, M. and Clark, A. (I996). Early bilingual acquisition of the voicing contrast in English and Spanish. Journal of Phonetics, 24: 35I-365.

Domahs, U., Wiese, R., Bornkessel-Schlesewsky, I. and Schlesewsky, M. (2008). The processing of German word stress: evidence for the prosodic hierarchy. Phonology, 25 : $\mathrm{I}-36$.

Fabiano-Smith, L. and Bunta, F. (2OI2). Voice onset time of voiceless bilabial and velar stops in 3-year-old bilingual children and their age-matched monolingual peers. Clinical Linguistics and Phonetics, 26.2: I48-I63.

Fischer-Jørgensen, E. (I972). PTK et BDG français en position intervocalique accentuée. In: A. Valdman (ed.), Papers in Linguistics and Phonetics to the Memory of Pierre Delattre. Mouton: The Hague, pp. I43-200.

Fischer-Jørgensen, E. (1976). Some data on North German stops and affricates. Annual Report of the Institute of Phonetics of the University of Copenhagen, IO: I49-200.

Flege, J. E. (1984). The detection of French accent by American listeners. Journal of the Acoustical Society of America, 76.3: 692-707.

Flege, J. E. (1995). Second language speech learning. Theory, findings, and problems. In: W. Strange (ed.), Speech Perception and Linguistic Experience: Issues in Cross-Language Research. Timonium, MD: York Press, pp. 233-277.

Flege, J. E. and Eefting, W. (1987). Cross language switching in stop consonant perception and production by Dutch speakers of English. Speech Communication, 6: I85-202.

Flege, J. E. and Hammond, R. M. (1982). Mimicry of non-distinctive phonetic differences between language varieties. Studies in Second Language Acquisition, 5.I: I-I 7 .

Flores, C. (2010). The effect of age on language attrition: Evidence from bilingual returnees. Bilingualism: Language and Cognition, I3.4: 533-546.

Fowler, A. C., Sramko, V., Ostry, D. J., Rowland, S. A. and Hallé, P. (2008). Cross language phonetic influences on the speech of French-English bilinguals. Journal of Phonetics, 36: 649-663. 
Gabriel, C. (2002). Französische Präpositionen aus generativer Sicht. Tübingen: Niemeyer.

Galmiche, M. (1986). Référence indéfinie, événements, propriétés et pertinence. In: J. David and G. Kleiber (eds), Déterminants: syntaxe et sémantique. Paris: Klincksieck, pp. 4I-7I.

Genesee, F. and Nicoladis, E. (2007). Bilingual first language acquisition. In: E. Hoff and M. Shatz (eds), Handbook of Language Development. Malden, MA: Blackwell Publishing, pp. 324-342.

Granfeldt, J. (2005). The development of gender assignment in bilingual first and second language French. In: J.-M. Dewaele (ed.), Focus on French a Foreign Language: Multidisciplinary Approaches. Clevedon: Multilingual Matters, pp. I64I90.

Granfeldt, J., Schlyter, S. and Kilhstedt, M. (2007). French as cL2, 2LI and LI in pre-school children. In: J. Granfeldt (ed.), PERLES 24. Studies in Romance Bilingual Acquisition-Age of Onset and Development of French and Spanish. Lund University, pp. $7-42$.

Haag, W. K. (I979). An articulatory experiment on voice onset time in German stop consonants. Phonetica: International Journal of Phonetic Science, 36: 169-I8 I.

Håkansson, G. (I995). Syntax and morphology in language attrition: a study of five bilingual expatriate Swedes. International Journal of Applied Linguistics, 5.2: I53I69.

Jesney, K. (2004). The Use of Global Foreign Accent Rating in Studies of L2 Acquisition. Annotated Bibliography, Language Research Centre University of Calgary.

Karmiloff-Smith, A. (I979). A Functional Approach to Child Language. A Study of Determiners and Reference. Cambridge: Cambridge University Press.

Kehoe, M. M., Lleó, C. and Rakow, M. (2004). Voice onset time in bilingual GermanSpanish children. Bilingualism: Language and Cognition, 7.I: 7I-88.

Kewley-Port, D. and Preston, M. S. (I974). Early apical stop production: A voice onset time analysis. Journal of Phonetics, 2.3: 195-2 Io.

Kupisch, T. (2OI2). Specific and generic subjects in the Italian of German-Italian simultaneous bilinguals and L2 learners. Bilingualism: Language and Cognition, I 5.4: 736-756.

Kupisch, T., Müller, N. and Cantone, K. F. (2002). Gender in monolingual and bilingual first language acquisition: Comparing Italian and French. Lingue e Linguaggio, I: I07I 49 .

Kupisch, T. and Pierantozzi, C. (2010). Interpreting definite plural subjects: A comparison of German and Italian monolingual and bilingual children. In: K. Franich, K. M. Iserman and L. L. Keil (eds), 34th BUCLD Proceedings. Boston: Boston University Press, pp. 245-254.

Laenzlinger, C. (2000). French adjective ordering: Perspectives on DP-internal movement types. Generative Grammar in Geneva, I: 55-IO4.

Laeufer, C. (1996). The acquisition of a complex phonological contrast: voice timing patterns of English initial stops by native French speakers. Phonetica: International Journal of Phonetic Science, 53. I-2: 86-I Io.

Lisker, L. and Abramson, A. S. (I964). A cross-language study of voicing in initial stops: acoustical measurements. Word, 20: $384-422$.

Lyster, R. (2006). Predictability in French gender attribution: a corpus analysis. Journal of French Language Studies, 16: 69-92. 
Macken, M. A. and Barton, D. (I979). The acquisition of the voicing contrast in English: a study of voice onset time in word-initial stop consonants. Journal of Child Language, 7.I: 4I-74.

Macken, M. A. and Barton, D. (I980). The acquisition of the voicing contrast in Spanish: a phonetic and phonological study of word-initial stop consonants. Journal of Child Language, 7.3: 433-458.

MacLeod, A. A. N. and Stoel-Gammon, C. (2009). The use of voice onset time by early bilinguals to distinguish homorganic stops in Canadian English and Canadian French. Applied Psycholinguistics, 30.1: 53-77.

MacLeod, A. A. N. and Stoel-Gammon, C. (2010). What is the impact of age of second language acquisition on the production of consonants and vowels among childhood bilinguals? International Journal of Bilingualism, I 4.4: 400-42 I.

Major, R. C. (1987). English voiceless stop production by speakers of Brazilian Portuguese. Journal of Phonetics, I5: 197-202.

Major, R. C. (1992). Losing English as a first language. The Modern Language Journal, 76.2: $190-208$.

Meisel, J. M. (ed.) (I990). Two First Languages: Early Grammatical Development in Bilingual Children. Dordrecht: Foris.

Meisel, J. M. (ed.) (1994). Bilingual First Language Acquisition: French and German Grammatical development. Amsterdam: John Benjamins.

Meisel, J. M. (1995). Parameters in acquisition. In: P. Fletcher and B. MacWhinney (eds), Handbook of Child Language. Oxford: Blackwell, pp. Io-35.

Meisel, J. M. (2009). Second language acquisition in early childhood. Zeitschrift für Sprachwissenschaft, 28.1: 5-34.

Meisel, J. M. (20I I). First and Second Language Acquisition: Parallels and Differences. Cambridge: Cambridge University Press.

Montrul, S. (2006). Incomplete acquisition as a feature of bilingual and L2 grammars. In: R. Slabakova, S. Montrul and P. Prévost (eds), Inquiries in Linguistic Development: In Honor of Lydia White. Amsterdam: Benjamins, pp. 335-359.

Montrul, S. (2008). Incomplete Acquisition in Bilingualism. Re-examining the Age-Factor. Amsterdam: Benjamins.

Montrul, S. (2009). Re-examining the Fundamental Differences Hypothesis: What can early bilinguals tell us? Studies in Second Language Acquisition, 3 I.2: 225-257.

Montrul, S., Foote, R. and Perpinán, S. (2008). Gender agreement in adult second language learners and adult Spanish heritage speakers: The effects of age and context of acquisition. Language Learning, 58.3: 503-553.

Montrul, S. and Ionin, T. (20 Iо). Transfer effects in the interpretation of definite articles by Spanish heritage speakers. Bilingualism: Language and Cognition, I 3: 449-473.

Moyer, A. (1999). Ultimate attainment in L2 phonology. Studies in Second Language Acquisition, 21: 8 I-I08.

Müller, N. (1990). Developing two gender assignment systems simultaneously. In: J. M. Meisel (ed.), Two First Languages: Early Grammatical Development in Bilingual Children. Amsterdam: Benjamins, pp. I93-234.

Müller, N. (1993). Komplexe Sätze: der Erwerb von COMP und von Wortstellungsmustern bei bilingualen Kindern (Französisch/Deutsch). Narr: Tübingen.

Müller, N. (1999). Gender and number in acquisition. In: B. Unterbeck and M. Rissanen (eds), Gender in Grammar and Cognition. Berlin/New York: De Gruyter, pp. $35 \mathrm{I}-399$. 
Neuhauser, S. (20II). Foreign accent imitation and variation of VOT and voicing in plosives. Proceedings of the XVIIth International Congress of Phonetic Science, Hong Kong, I $462-I 465$.

Nicoladis, E. (2006). Cross linguistic transfer in adjective-noun strings by preschool bilingual children. Bilingualism: Language and Cognition, 9. I: I 5-32.

Paradis, J. and Genesee, F. (I996). Syntactic acquisition in bilingual children: Autonomous or interdependent? Studies in Second Language Acquisition, I 8: I-I 5.

Pearson, B. Z., Fernández, S. C., Lewedeg, V. and Oller, D. K. (I997). The relation of input factors to lexical learning by bilingual infants. Applied Psycholinguistics, I 8: $4 \mathrm{I}-58$.

Pérez-Leroux, A., Munn, A., Schmitt, C. and DeIrish, M. (2004). Learning definite determiners: genericity and definiteness in English and Spanish. In: B. Beachley, A. Brown and F. Conlin (eds), Proceedings Supplement of the $28^{\text {th }}$ BUCLD, pp. I-I2.

Piske, T., MacKay, I. R. A. and Flege, J. E. (200I). Factors affecting degree of foreign accent in an L2: a review. Journal of Phonetics, 29: I9I-2I 5.

Polinsky, M. (1997). American Russian: Language loss meets language acquisition. In: W. Browne et al. (eds), Annual Workshop on Formal Approaches to Slavic Linguistics, Cornell Meeting (1995). Ann Arbor: Michigan Slavic Publications, pp. 370-406.

Polinsky, M. (2008). Gender under incomplete acquisition: Heritage speakers' knowledge of noun categorization. Heritage Language Journal, 6.I: 40-7I.

Rizzi, S., Gil, L., Müller, J. and Müller, N. (20I3). Adjective placement in bilingual Romance-Romance and Romance-German children with special reference to Romance (French, Italian and Spanish). Studia Linguistica 67.I: I23-I47.

Rothman, J. (2009). Understanding the nature and outcomes of early bilingualism: Romance languages as heritage languages. International Journal of Bilingualism, I3.2: I $55-\mathrm{I} 63$.

Royle, P. and Valois, D. (2010). Acquisition of adjectives in Quebec French as revealed by elicitation data. Journal of French Language Studies, 20: 3 I 3-338.

Schmid, M. and Köpke, B. (2008). Li attrition and the mental lexicon. In: A. Pavlenko (ed.), The Bilingual Mental Lexicon. Clevedon: Multilingual Matters, pp. 209-238.

Serratrice, L., Sorace, A., Filiaci, F. and Baldo, M. (2009). Bilingual children's sensitivity to specificity and genericity: Evidence from metalinguistic awareness. Bilingualism: Language and Cognition, I2: 239-257.

Sorace, A. (1993). Incomplete vs. divergent representations of unaccusativity. Second Language Research, 9. I: 22-47.

Sorace, A. and Serratrice, L. (2009). Internal and external interfaces in bilingual language development: Beyond structural overlap. International Journal of Bilingualism, I3: II6.

Stoel-Gammon, C. (1985). Phonetic inventories, I 5-24 months. Journal of Speech and Hearing Research, 28: 505-512.

Sundara, M. and Polka, L. (2008). Discrimination of coronal stops by bilingual adults: The timing and nature of language interaction. Cognition, I06.I: 234258.

Sundara, M., Polka, L. and Baum, S. (2006). Production of coronal stops by simultaneous bilingual adults. Bilingualism: Language and Cognition, 9: 97-I I4.

Tucker, G. R., Lambert, W. E. and Rigault, A. A. (1977). The French Speaker's Skill with Grammatical Gender: An Example of Rule-Governed Behavior. The Hague: Mouton.

Walker, D. C. (1975). Word stress in French. Language, 51.4: 887-900. 


\section{Tanja Kupisch et al.}

Watson, I. (1990). Acquiring the voicing contrast in French: A comparative study of monolingual and bilingual children. In: J. N. Green and W. Ayres-Bennett (eds), Variation and Change in French: Essays Presented to Rebecca Posner on the Occasion of her Sixtieth Birthday. London: Routledge, pp. 37-60.

White, L. (2009). Grammatical theory: Interfaces and L2 knowledge. In: W. B. Ritchie and T. K. Bhatia (eds), The New Handbook of Second Language Acquisition. Bingley, UK: Emerald Group Publishing, pp. 49-68. 